\title{
Temporal influence of endocrine therapy with tamoxifen and chemotherapy on nutritional risk and obesity in breast cancer patients
}

Mariana Tavares Miranda Lima', Kamila Pires de Carvalho ${ }^{1}$, Fernanda Silva Mazzutti ${ }^{2}$, Marcelo de Almeida Maia ${ }^{3}$, Paula Philbert Lajolo Canto ${ }^{4}$, Carlos Eduardo Paiva ${ }^{5}$ and Yara Cristina de Paiva Maia ${ }^{1,2^{*}}$

\begin{abstract}
Background: The effect of endocrine therapy with tamoxifen (TMX) on weight gain has been reported in the literature, but the outcomes are still controversial. Moreover, previous treatment options, such as chemotherapy $(C T)$, also include body changes. The focus of this study was to verify the temporal influence of endocrine therapy with TMX on nutritional risk and obesity and its association with $C T$ in breast cancer patients.

Methods: In this cross-sectional study, 84 breast cancer surviving women were evaluated during endocrine therapy with TMX. Anthropometric, biochemical and body composition parameters were measured. A generalized estimating equation (GEE) was used to examine the association between $C T$ and groups of women using TMX categorized by the duration of the treatment (group 1, women using TMX for the first 3 years; group 2, women using TMX between 3 and 4 years and group 3, women using TMX for more than 4 years).

Results: The interaction of $C T$ with duration of TMX use showed a significant effect on Body Mass Index (BMI), waist circumference (WC) and body fat percentage (BFP) (GEE $p$-value $=0.002,0.000,0.000$, respectively). Women from group 1 who underwent $C T$ presented higher values of body variables compared to those women from group 2 who also underwent $C \mathrm{CT}\left(\mathrm{BMl}=29.14 \pm 0.93,26.76 \pm 0.85 \mathrm{~kg} / \mathrm{m}^{2} ; \mathrm{WC}=94.45 \pm 1.96,91.07 \pm 2.44 \mathrm{~cm} ; \mathrm{BFP}=36.36 \pm 1.50,33.43 \pm\right.$ $1.66 \%$, respectively). On the other hand, women from group 1 who did not undergo $C T$ presented lower values of body variables compared to those women from group 2 who also did not undergo CT (BMl $=25.29 \pm 0.46,28.40 \pm 0.95 \mathrm{~kg} / \mathrm{m}^{2}$; $W C=85.84 \pm 0.90,97.75 \pm 0.88 \mathrm{~cm} ; \mathrm{BFP}=30.32 \pm 0.43 ; 42.95 \pm 1.03 \%$, respectively).

Conclusions: Women on endocrine therapy with TMX are mostly overweighed and obese, most evidently in women who received $C T$, and who were at the beginning of treatment. Women that did not undergo $C T$, despite presenting lower values of body variables in the first 3 years, still deserve special attention because significantly higher values were observed in women between 3 and 4 years of therapy.
\end{abstract}

Keywords: Breast neoplasm, Endocrine therapy, Tamoxifen, Chemotherapy, Body composition, Body weight

\footnotetext{
* Correspondence: yara.maia@ufu.br

'Graduate Program in Health Sciences, Federal University of Uberlandia,

Avenida Pará, 1720 Bloco 2U, Campus Umuarama, Uberlandia, Minas Gerais

CEP 38400-902, Brazil

${ }^{2}$ Nutrition Course, Medical Faculty, Federal University of Uberlandia, Avenida

Pará, 1720 Bloco 2U, Campus Umuarama, Uberlandia, Minas Gerais CEP

38400-902, Brazil

Full list of author information is available at the end of the article
}

(c) The Author(s). 2017 Open Access This article is distributed under the terms of the Creative Commons Attribution 4.0 International License (http://creativecommons.org/licenses/by/4.0/), which permits unrestricted use, distribution, and reproduction in any medium, provided you give appropriate credit to the original author(s) and the source, provide a link to the Creative Commons license, and indicate if changes were made. The Creative Commons Public Domain Dedication waiver (http://creativecommons.org/publicdomain/zero/1.0/) applies to the data made available in this article, unless otherwise stated. 


\section{Background}

Breast cancer (BC) accounts for $29 \%$ of all new cases of cancer in women, being the second leading cause of death [1]. In patients treated with surgery, adjuvant endocrine therapy with tamoxifen (TMX), a selective estrogen receptor modulator, has been widely used in individuals expressing estrogen and/or progesterone endocrine receptors [2], prolonging substantially disease-free intervals and survival outcomes [3].

Changes in body weight are described as side effects during treatment [4-6]. Both the initial overweight and the amount of weight gained during treatment negatively influence the prognosis, survival and quality of life of women with $\mathrm{BC}$ [7-9]. In endocrine therapy, even though this gain is more modest ( 1 to $2 \mathrm{~kg}$ ) [10,11] when compared to the CT period ( 3 to $7 \mathrm{~kg}$ ) [12-14], it is a major concern regarding non-adherence to endocrine therapy [15]. Furthermore, even without weight gain, these women are affected by changes in body composition with loss of muscle mass and an increase in body fat percentage (BFP) $[10,16]$. The excess of BFP in postmenopausal women results in increased estrogen and androgen concentrations in adipose tissue [17], which can stimulate cancer cells [18], change circulating levels of pro-inflammatory cytokines [19], and also impact the efficiency of TMX [20]. However, these results are still unclear and need to be further investigated.

Furthermore, metabolic implications at the beginning of treatment for $\mathrm{BC}$ reveal impairment of glucose metabolism and dyslipidemia [21] and extend into survivors on endocrine therapy with TMX [22-24]. These implications are important along with weight gain due to the occurrence of cardiovascular diseases that may develop over time in postmenopausal women on endocrine therapy with TMX $[25,26]$. However, even in face of these implications, the overall beneficial effects of treatments for BC are already established [2, 3]. Also, the combination of treatments for BC, such as chemotherapy (CT) plus TMX, promotes substantial benefits compared to CT alone, producing a further reduction in recurrence risk [2].

Considering the recommendation to use endocrine therapy with TMX for up to 10 years [3], the impact of body modifications on survival and disease recurrence during endocrine therapy is poorly understood [27, 28]. In this sense, knowing the potential long-term effect of previous treatments, such as CT $[12,13]$, it is necessary to understand its influence on the TMX side effects related to anthropometric parameters and BFP at different moments of endocrine therapy. In addition, this understanding will enable the development of multidisciplinary interventions directed throughout the treatment.

We hypothesized that women who underwent CT were more obese and that the degree of obesity was more evident at the beginning of TMX therapy. Thus, the objective of this study was to analyze the temporal influence of endocrine therapy with TMX on nutritional risk and obesity and its association with $\mathrm{CT}$ in $\mathrm{BC}$ patients, evaluated by means of anthropometric variables and body composition.

\section{Methods \\ Ethical aspects}

A transversal study conducted in 2015-2016 in a brazilian university hospital (HC-UFU, Uberlandia, Minas Gerais, Brazil) including one assessment with $\mathrm{BC}$ patients during endocrine therapy with TMX, in the period from August 2015 to March 2016.

This study was approved by the Human Research Ethics Committee (protocol number 907.129/14) and the entire study was conducted based on the standards of the Helsinki Declaration. All participants signed a free and informed consent form.

\section{Sample size calculation}

The sample size required for this study was determined using the $G *$ Power software, version 3.1 [29]. The sample size calculations were based on an $\mathrm{F}$ test linear multiple regression with effect size f of 0.15 , an alpha level of 0.05 , $95 \%$ power and 3 predictors. Given the output Parameter, a total sample of 84 women was required at final analysis.

\section{Eligibility criteria}

The study included women diagnosed with $\mathrm{BC}$ with indication of endocrine therapy with TMX and with verbal and cognitive capacity to respond to the instruments used for data collection. Women older than or equal to 80 years and less than or equal to 18 years were excluded from the study, as well as patients with locoregional or distant $\mathrm{BC}$ recurrence; diagnosis of any other type of cancer; autoimmune diseases and/or use of corticosteroids; presence of diabetes mellitus; thyroid diseases; depressive syndrome; pregnant or postpartum women; admission to palliative care programs; institutionalized patients; without telephone contact; previous use of TMX and/or change to the use of aromatase inhibitors.

\section{Participants for recruitment}

The active medical records of patients being treated with TMX in the month of March 2015 were analyzed $(n=412)$ and 231 patients were classified as eligible for the study. Using a table of random numbers, 84 patients were invited to participate in the study according to the previously calculated sample. Groups were set according to the duration of TMX use, obtained by stratification into tertiles at three times of use (groups 1, 2 and 3), considering equivalent ranges of the duration: group 1 included 32 women using TMX for the first 3 years; group 2 included 22 women using TMX between 3 to 
4 years; and group 3 included 30 women using TMX for more than 4 years (maximum time equals to 6 years and 6 months). The three groups included, after strict eligibility criteria, both women who underwent chemotherapy along with those who did not undergo (Fig. 1). The invitation to participate was made by phone and the evaluations were carried out at the oncology department of the clinical hospital.

\section{Anthropometric assessment}

A mechanical scale was used to measure weight, with sensitivity of $100 \mathrm{~g}$; for height, a vertical stadiometer with a $1 \mathrm{~mm}$ precision scale was used; and for waist circumference (WC) a flexible and inelastic tape was used, following the protocol recommended by the World Health Organization [30]. After obtaining these measurements, the Body Mass Index (BMI) were calculated dividing weight by height squared $\left(\mathrm{Kg} / \mathrm{m}^{2}\right)$, taking into consideration elderly women over 60 years of age [31].

The horizontal tetra polar bioelectrical impedance (BIA) (Biodynamics device model 450) was used to evaluate body compartments, using the cutoff point for excess BFP in women $\geq 24 \%$ [32]. Participants were guided regarding the protocol of the test [33].

\section{Quantitative dietary assessment}

Properly trained nutritionists collected information about food consumption by means of a 24-h dietary recall (24HR) applied through telephone interviews, according to the technique used in the Vigitel Study [34] with adaptations. For each participant, three nonconsecutive $24 \mathrm{HR}$ were applied, including a day of the weekend, in order to better reflect the eating habits of the participants. From the $24 \mathrm{HR}$, the mean quantity of total energy, carbohydrate, protein and lipid were estimated. Quantification of nutrients was performed through Dietpro $^{\oplus}$ software, version 5.7, using as a reference, preferably, the Brazilian Table of Food Composition [35]. However, for those foods not found in this table, the international reference was used, the table from the United States Department of Agriculture [36].

\section{Laboratory assays}

Venous blood was collected at the time of the interview, between 7 am and 10 am, after overnight fasting and under standard conditions for analysis of Total Cholesterol, LDL Cholesterol (LDL-C), HDL Cholesterol (HDL-C) (mg/dL), TG (mg/dL), Fasting glucose (mg/dL), C Reactive Protein (CRP) $(\mathrm{mg} / \mathrm{dL})$, and a complete blood count. The results were evaluated according to recommendations established in the literature [37-39].

\section{Statistical analyses}

First, the Kolmogorov-Smirnov normality test was performed. Parametric tests for variables with normal

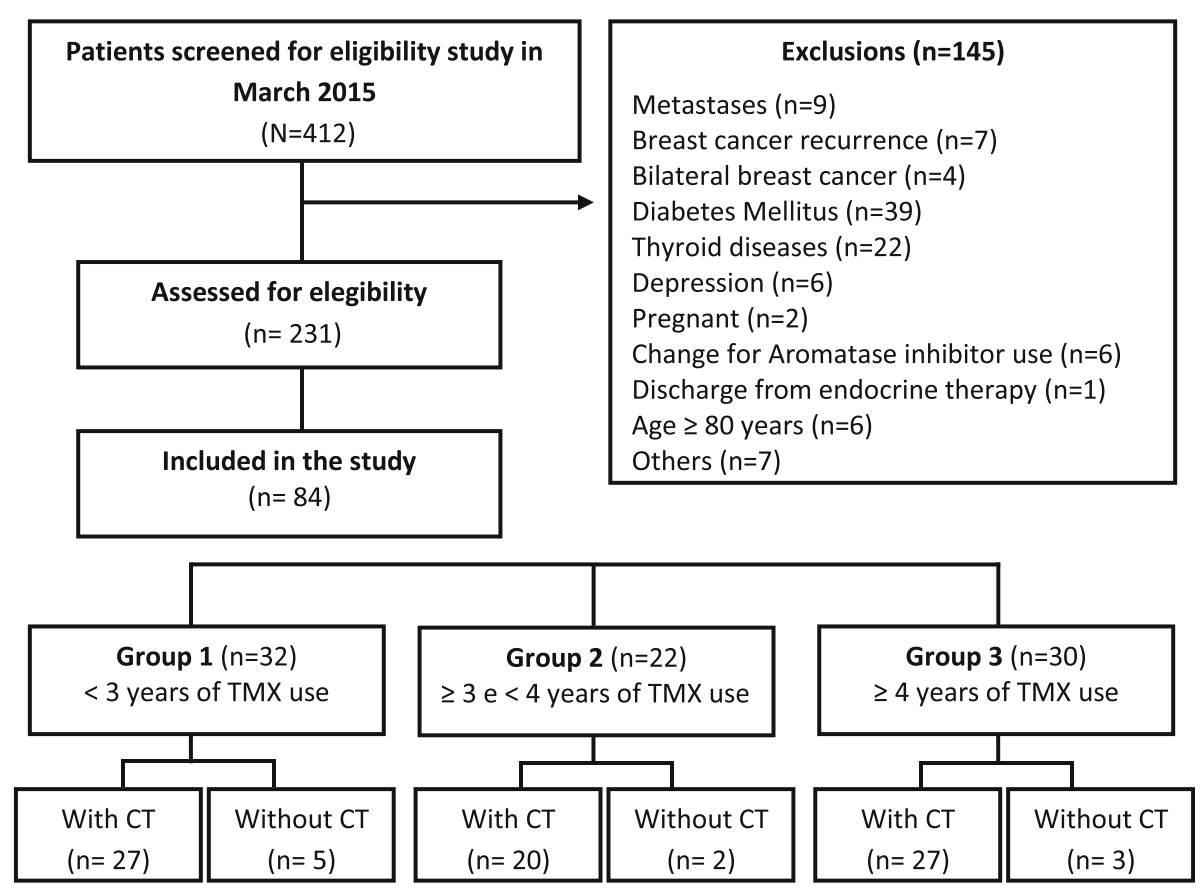

Fig. 1 Diagram reporting the number of women screened and recruited in this study $(n=84)$. Diagram reporting the number of women with breast cancer on endocrine therapy with tamoxifen screened and recruited during the study conducted at a university hospital in the city of Uberlandia, Minas Gerais, Brazil, 2015-2016 ( $n=84)$. Group 1, women using tamoxifen for the first 3 years; group 2, women using tamoxifen between 3 and 4 years; Group 3, women using tamoxifen for more than 4 years; $C T$, chemotherapy; TMX, tamoxifen 
distribution, or non-parametric tests for variables without normal distribution were performed. Generalized Estimating Equations (GEE) were used to examine the association between groups of TMX/CT and nutritional risk and obesity at first, second and third usage time adjusting for age, smoking, alcohol consumption, physical activity, energy (kcal), and clinical stage. An interaction term between the CT and time was included in the model. The GEE model accounts for correlations among the within-subject outcome variables of BMI, WC and BFP and provides consistent estimates of the parameters of the standard errors using robust estimators. The adjustment method for multiple comparisons was Sequential Sidak. All statistical analyses were run using the SPSS $^{\oplus}$ (SPSS, Inc., Chicago, USA) software package (SPSS Statistics for Windows, version 21) and a $p$-value $\leq 0.05$ was considered statistically significant.

\section{Results}

The study included 84 women with mean age of $53.11 \pm 8.73$ years. Socio-demographic, clinical, hormonal and therapeutic characteristics are presented in Table 1. Most women $(52.4 \%, n=44)$ considered themselves white, reported monthly income higher than 3 minimum wages $(46.5 \%, n=39)$ and low education level (42.9\%, $n=36)$. Regarding clinical and hormonal characteristics, 91.7\% ( $n=77)$ were found to be postmenopausal and 90.5\% $(n=76)$ presented invasive ductal carcinoma. As for the molecular phenotype, the majority (51.2\%, $n=43$ ) was classified as luminal B. Regarding surgical procedures, $52.4 \%(n=44)$ of the women underwent conservative breast surgery and $46.5 \%(n=39)$ had mastectomy. The percentage of patients submitted to adjuvant chemotherapy was $58.3 \%(n=49), 29.8 \%$ $(n=25)$ to the neoadjuvant and $11.9 \%(n=10)$ did not undergo chemotherapy. The majority were treated with adriamycin + cyclophosphamide + docetaxel (AC-T) regimen $(42.9 \%, n=36)$ followed by cyclophosphamide, doxorubicin and 5-fluorouracil (FAC) $(25.0 \%, n=21)$.

Regarding the anthropometric parameters, the current BMI values $63.1 \%$ of participants were above the values of eutrophy for adults and elderly (26.79 \pm 4.59; $28.16 \pm 4.53 \mathrm{~kg} / \mathrm{m}^{2}$, respectively). When comparing the groups, the BMI values of adults were significantly higher among women in group $1\left(28.38 \pm 4.12 \mathrm{~kg} / \mathrm{m}^{2}\right.$, $p=0.018)$ when compared with the others. No statistically significant difference was found between the groups for the BMI of the elderly. In addition, among the BMI classifications, women who underwent CT $(n=74)$, $62.2 \%(n=46)$ were classified as overweighed or obese and $37.8 \%(n=28)$ were neither overweighed nor obese, considering adults and elderly. For those who did not undergo CT $(n=10), 70.0 \%(n=7)$ were classified as overweight and $30.0 \%(n=3)$ as non-overweighed. The
BFP and WC presented mean values above the recommendations $(35.23 \pm 7.55 \%, 90.63 \pm 11.07 \mathrm{~cm}$, respectively), but without significant differences when compared between groups (Table 2).

The blood analysis for the lipid parameters showed discretely altered values of TG and HDL-C (153.49 \pm 85.21; $55.19 \pm 17.92 \mathrm{mg} / \mathrm{dL}$, respectively). Comparing the groups, significantly worse values of HDL-C in group 2 were observed compared to groups 1 and 3 $(47.51 \pm 19.75 ; 53.34 \pm 16.62 ; 62.78 \pm 15.29 \mathrm{mg} / \mathrm{dL}$, $p=0.006$, respectively). The same was not observed for TG when comparing the groups. For hemoglobin, WBC, platelets and CRP the values were within the recommended values (Table 2).

Regarding food intake, we did not find a statistically significant difference for the average amount of energy, carbohydrate and protein ingested among the three groups. However, lipids had significantly higher mean values in group 1 than in groups 2 and $3(66.74 \pm 25.93$, $48.61 \pm 18.14,56.61 \pm 19.06 \mathrm{~g}$, respectively, $p=0.012$ ).

In the GEE analyses, we did not find significant isolated effects of CT on BMI, WC and BFP ( $p=0.102$, $p=0.084, p=0.607$, respectively). However, significant effects were observed when we evaluated the duration of TMX use (determined by the three groups) on WC and BFP $(p=0.003$ and $p=0.001$, respectively). Furthermore, the interaction between these two factors (CT and duration of TMX use) was significant for all anthropometric and body composition parameters $(p<0.05)$ (Table 3$)$.

Table 4 shows the post hoc comparisons of the variables evaluated with $\mathrm{CT}$ and not $\mathrm{CT}$ and groups 1, 2 and 3. Analyses of the univariate effects showed that in group 1, women who did CT when compared with those who did not undergo CT, presented significantly higher values of BMI $\left(29.14 \pm 0.93 ; 25.29 \pm 0.46 \mathrm{~kg} / \mathrm{m}^{2}\right.$, $p=0.003, \quad$ respectively), WC $(94.45 \pm 1.96$; $85.84 \pm 0.90 \mathrm{~cm}, p=0.001$, respectively) and BFP $(36.36 \pm 1.50 ; 30.32 \pm 0.43 \%, p=0.001$, respectively). In group 2, the tendency is inverse, i.e., women that underwent CT presented lower values for BMI, WC and BFP, but only for BFP was significantly lower $(33.43 \pm 1.66$; $42.95 \pm 1.03 \% ; p=0.000$ ).

Comparing women who underwent CT, no statistically significant differences were observed between the groups, even though mean values were higher in group 1 when compared to group 2 for BMI $(29.14 \pm 0.93$; $26.76 \pm 0.85, \mathrm{~kg} / \mathrm{m}^{2}$, respectively), WC (94.45 \pm 1.96 ; $91.07 \pm 2.44 \mathrm{~cm}$, respectively) and BFP (36.36 \pm 1.50 ; $33.43 \pm 1.66 \%$, respectively) (Table 4 ).

Comparing women who did not undergo $\mathrm{CT}$, we had significant differences between groups. Comparing women from groups 1 and 2, mean values were significantly lower for group 1 compared to group 2 for BMI $\left(25.29 \pm 0.46 ; 28.40 \pm 0.95 \mathrm{~kg} / \mathrm{m}^{2}, \quad p=0.042\right.$, 
Table 1 Sociodemographic, clinical, hormonal and therapeutic characteristics $(n=84)$

\begin{tabular}{l} 
Characteristics \\
\hline Race \\
White \\
Black \\
Hispanic \\
Income, R\$ ${ }^{\text {I }}$ \\
440-880 \\
$881-1.760$ \\
$>1.761$ \\
Education \\
Elementary School - Incomplete \\
Elementary School - Complete \\
High School - Incomplete \\
High School - Complete \\
Graduate degree \\
Menopausal status \\
Premenopausal \\
Postmenopausal \\
Tumoral Subtype \\
Ductal \\
Lobular \\
Mucinous \\
Ducto-Lobular \\
IInical Stage \\
\hline
\end{tabular}

Tumor grade

G1

G2

G3

NR

Molecular Subtypes

Luminal A

Luminal B

NR

Surgery

Breast-conserving surgery

Mastectomy

No surgery

Chemotherapy

Adjuvant

Neoadjuvant

No chemotherapy

$6(7.1)$

$7(8.3)$

$4(4.8)$

$3(3.6)$

$1(1.2)$

$7(8.3)$

$5(6.0)$

$4(4.8)$

$1(1.2)$
Table 1 Sociodemographic, clinical, hormonal and therapeutic characteristics ( $n=84)$ (Continued)

Chemotherapy Regimen

$A C+$ Docetaxel

$36(42.9)$

FAC

$21(25.0)$

$9(10.7)$

$31(36.9)$

CMF

$18(21.4)$

NR not reported, G1 well-differentiated tumor (low grade), G2 moderately differentiated tumor (intermediate grade), G3 poorly differentiated tumor (high grade), $A C$ adriamycin + cyclophosphamide, $F A C$ cyclophosphamide, doxorubicin,

$14(16.7)$

$31(36.9)$

39 (46.5)

$36(42.9)$

$9(10.7)$

$21(25.0)$

$12(14.3)$

$77(91.7)$

$76(90.5)$

$21(25.0)$

$49(58.3)$

$14(16.7)$

$11(13.1)$

61 (72.6)

$37(44.0)$

$43(51.2)$

$44(52.4)$

39 (46.5)

$49(58.3)$

25 (29.8)

$10(11.9)$

and 5-fluorouracil, CMF cyclophosphamide, methotrexate, and 5-fluorouracil

${ }^{a}$ Minimum wage per month, $\mathrm{R} \$ 880,00$

respectively), WC (85.84 $\pm 0.90 ; 97.75 \pm 0.88 \mathrm{~cm}$, $p=0.000$, respectively) and BFP (30.32 \pm 0.43 ; $42.95 \pm 1.03, p=0.000$, respectively). Furthermore, comparing group 2 with group 3, for those women who did not undergo $\mathrm{CT}$, mean values were lower for $\mathrm{BMI}, \mathrm{WC}$, and BFP, but only for WC the difference was significant $(97.75 \pm 0.88 ; 76.00 \pm 7.02 \mathrm{~cm}$, respectively, $p=0.025)$ (Table 4).

Figure 2 shows the post hoc comparisons for BMI, $\mathrm{WC}$ and BFP values of women who underwent CT and who did not undergo CT, grouped by TMX time usage (groups 1, 2 and 3).

\section{Discussion}

In our study, we observed that the majority of women in endocrine therapy with TMX were classified as overweighed and obese, and we investigated the association of CT, usage time of TMX, and three different body parameters (BMI, WC and BFP). Although we did not find an isolated effect of $\mathrm{CT}$, the interaction of $\mathrm{CT}$ with duration of TMX use showed a significant effect on BMI, WC and BFP. In our study, women from group 1 who did not undergo CT, presented lower values of body variables compared to those women who also did not undergo CT but were using TMX between 3 to 4 years (group 2). On the other hand, women from group 1 who underwent CT, presented higher values of body variables compared to those women who also underwent CT but were using TMX between 3 to 4 years (group 2). So, our study provides relevant knowledge to understand the need for specific and targeted conducts at different times of endocrine therapy.

In the present study we found values above the recommendations of weight and body fat excess in women on endocrine therapy with TMX, results similar to those observed in the literature [40, 41]. These body modifications related to increased adipose tissue lead to unsatisfactory outcomes, especially in postmenopausal women with BC [42-45]. However, these outcomes of weight gain during endocrine treatment with TMX are still controversial and need to be further investigated [13, 46, 47]. One of those outcomes could be an abnormally high 
Table 2 Characterization of the anthropometric and biochemical variables evaluated according to the groups established by the duration of tamoxifen use $(n=84)$

\begin{tabular}{|c|c|c|c|c|c|c|}
\hline \multirow[t]{2}{*}{ Variables } & & \multicolumn{5}{|l|}{ Mean \pm SD } \\
\hline & & Total $(n=84)$ & Group $1(n=32)$ & Group $2(n=22)$ & Group $3(n=30)$ & $p$-value \\
\hline Age (range: $33-73$ years) & & $53.11 \pm 8.73$ & $51.37 \pm 7.35$ & $54.09 \pm 9.18$ & $54.23 \pm 9.69$ & 0.37 \\
\hline \multicolumn{7}{|l|}{ Anthropometric } \\
\hline \multicolumn{7}{|l|}{ Current BMI $\left(\mathrm{Kg} / \mathrm{m}^{2}\right)$} \\
\hline Adults $(n=62)$ & & $26.79 \pm 4.59$ & $28.38 \pm 4.12$ & $26.76 \pm 4.29$ & $24.54 \pm 4.73$ & 0.018 \\
\hline Elderly ( $n=22$ ) & & $28.16 \pm 4.53$ & $29.40 \pm 7.87$ & $27.30 \pm 2.07$ & $28.07 \pm 3.86$ & 0.760 \\
\hline WC (cm) & & $90.63 \pm 11.07$ & $93.11 \pm 10.07$ & $91.67 \pm 10.83$ & $87.21 \pm 11.73$ & 0.096 \\
\hline $\operatorname{BFP}(n=74)$ & & $35.23 \pm 7.55$ & $35.55 \pm 7.53$ & $34.38 \pm 7.45$ & $35.54 \pm 7.92$ & 0.845 \\
\hline Biochemicals & Recommendation & & & & & \\
\hline TG & $<150 \mathrm{mg} / \mathrm{dL}$ & $153.49 \pm 85.21$ & $156.43 \pm 86.51$ & $181.45 \pm 102.83$ & $130.03 \pm 62.97$ & 0.095 \\
\hline $\mathrm{HDL}-\mathrm{C}$ & $>60 \mathrm{mg} / \mathrm{dL}$ & $55.19 \pm 17.92$ & $53.34 \pm 16.62$ & $47.51 \pm 19.75^{1}$ & $62.78 \pm 15.29^{1}$ & 0.006 \\
\hline LDL-C & $<100 \mathrm{mg} / \mathrm{dL}$ & $96.80 \pm 28.24$ & $94.79 \pm 25.18$ & $99.06 \pm 37.88$ & $97.30 \pm 23.61$ & 0.858 \\
\hline Blood glucose & $<100 \mathrm{mg} / \mathrm{dL}$ & $82.17 \pm 30.22$ & $78.41 \pm 35.90$ & $86.00 \pm 29.02$ & $83.37 \pm 24.47$ & 0.644 \\
\hline Hemoglobin & 12.0 a $15.5 \mathrm{~g} / \mathrm{dL}$ & $12.88 \pm 1.69$ & $12.63 \pm 2.54$ & $13.00 \pm 0.80$ & $13.05 \pm 0.83$ & 0.582 \\
\hline WBC & 3.500 a $10.500 \mathrm{mil} / \mathrm{mm}$ & $5916.55 \pm 1737.62$ & $5403.12 \pm 1589.95$ & $6232.27 \pm 1508.85$ & $6232.67 \pm 1954.68$ & 0.104 \\
\hline Platelets & 150 a $450 \mathrm{mil} / \mathrm{mm}$ & $194,142.9 \pm 65,099.0$ & $185,062.50 \pm 73,578.98$ & $198,772.73 \pm 68,529.40$ & $200,433.33 \pm 52.848 .31$ & 0.608 \\
\hline CRP & $<0.3 \mathrm{mg} / \mathrm{dL}$ & $0.42 \pm 0.64$ & $0.49 \pm 0.98$ & $0.37 \pm 0.31$ & $0.37 \pm 0.30$ & 0.698 \\
\hline \multicolumn{7}{|l|}{ Food consumption } \\
\hline Energy (kcal) & & $1591.63 \pm 526.80$ & $1742.62 \pm 580.62^{2}$ & $1393.56 \pm 449.09^{2}$ & $1575.83 \pm 482.39$ & 0.054 \\
\hline Energy (kJ) & & $6659.38 \pm 2204.13$ & $7291,12 \pm 2429,31^{2}$ & $5830,66 \pm 1878,99^{2}$ & $6593,27 \pm 2018,32$ & 0.054 \\
\hline Carbohydrate (g) & & $201.94 \pm 71.98$ & $212.01 \pm 67.38$ & $182.85 \pm 63.47$ & $205.19 \pm 81.60$ & 0.331 \\
\hline Protein (g) & & $65.09 \pm 25.02$ & $72.14 \pm 28.63$ & $56.66 \pm 21.86$ & $63.76 \pm 21.42$ & 0.076 \\
\hline Lipids (g) & & $58.37 \pm 22.69$ & $66.74 \pm 25.93^{3}$ & $48.61 \pm 18.14^{3}$ & $56.61 \pm 19.06$ & 0.012 \\
\hline
\end{tabular}

$B M I$ body mass index, WC waist circumference, $T G$ triglycerides, $H D L-C$ high density lipoprotein, $L D L-C$ low density lipoprotein, WBC white blood cell count, $C R P C$ Reactive Protein, SD standard deviation, Group 1 women using tamoxifen for the first 3 years, Group 2 women using tamoxifen between 3 and 4 years, Group 3 women using TMX for more than 4 years. The cutoff points of the biochemicals parameters were evaluated according to recommendations [37-39]; $p<0.05$ was considered significant, calculated by ANOVA

${ }^{1} p=0.006 ;{ }^{2} p=0.049 ;{ }^{3} p=0.010$

Table 3 Model effect tests of tamoxifen use duration groups and whether or not chemotherapy is performed

\begin{tabular}{lllll}
\hline Variable & Effect & df & Wald Chi-square & ${ }^{*} p$-value \\
\hline BMI & Duration of use & 2 & 3.16 & 0.206 \\
& CT & 1 & 2.68 & 0.102 \\
\multirow{3}{*}{ WC } & Duration of use $\times$ CT & 2 & 12.31 & 0.002 \\
& Duration of use & 2 & 11.88 & 0.003 \\
& CT & 1 & 2.99 & 0.084 \\
BFP & Duration of use x CT & 2 & 22.27 & 0.000 \\
& Duration of use & 2 & 14.29 & 0.001 \\
& CT & 1 & 0.27 & 0.607 \\
& Duration of use $\times$ CT & 2 & 37.95 & 0.000
\end{tabular}

BMI, Body Mass Index; WC, waist circumference; BFP, body fat percentage; $C T$, chemotherapy; General Estimated Equations (GEE). Data adjusted for age, smoking, alcohol consumption, physical activity, energy (kcal), and clinical stage. df, Degree of freedom

${ }^{*} p$ values calculated by ANOVA expression of the aromatase enzyme in the breast, an enzyme that is responsible for the production of increased local estrogen, thus predisposing the mammary tissue to hyperplasia and cancer [18], as well as a bioenergetic adaptation of the cancer cells [48, 49].

In this sense, due to the important association of overweight with the prognosis of the disease [7-9, 27, 28], it is necessary to identify possible predictors about the body changes that occur during endocrine therapy with TMX. In the present study, we found that CT alone showed no effect on nutritional risk and obesity. It is known, however, that adjuvant $\mathrm{CT}$ for $\mathrm{BC}$ acts as an independent prognostic factor for bodily modifications with a potential long-term effect and may therefore affect the period of endocrine therapy $[12,13]$. However, when we evaluated in this study the interaction between CT and duration of TMX use, we verified a significant effect on all body parameters evaluated, which demonstrates the relevance of that interaction in body changes 
Table 4 Post hoc comparison for the chemotherapy factor between the different groups of tamoxifen use duration

\begin{tabular}{|c|c|c|c|c|c|c|c|c|}
\hline \multirow[t]{3}{*}{ Variables } & \multirow[t]{3}{*}{ Groups } & \multicolumn{2}{|l|}{ Mean \pm SD } & \multirow[t]{3}{*}{${ }^{*} p$-value } & \multicolumn{4}{|c|}{ 95\% Wald Confidence Interval } \\
\hline & & \multirow[t]{2}{*}{ Without CT } & \multirow[t]{2}{*}{ With CT } & & \multicolumn{2}{|c|}{ Without CT } & \multicolumn{2}{|c|}{ With $C T$} \\
\hline & & & & & Lower & Upper & Lower & Upper \\
\hline \multirow[t]{3}{*}{ BMl } & 1 & $25.29^{1} \pm 0.46$ & $29.14 \pm 0.93$ & 0.003 & 24.41 & 26.20 & 27.39 & 31.02 \\
\hline & 2 & $28.40^{1} \pm 0.95$ & $26.76 \pm 0.85$ & 0.720 & 26.60 & 30.33 & 25.14 & 28.48 \\
\hline & 3 & $21.97 \pm 3.18$ & $26.27 \pm 0.83$ & 0.720 & 16.55 & 29.18 & 24.70 & 27.94 \\
\hline \multirow[t]{3}{*}{ WC } & 1 & $85.84^{2} \pm 0.90$ & $94.45 \pm 1.96$ & 0.001 & 84.10 & 87.62 & 90.68 & 98.38 \\
\hline & 2 & $97.75^{2,4} \pm 0.88$ & $91.07 \pm 2.44$ & 0.105 & 96.03 & 99.50 & 86.41 & 95.97 \\
\hline & 3 & $76.00^{4} \pm 7.02$ & $88.46 \pm 2.07$ & 0.429 & 63.40 & 91.10 & 84.49 & 92.61 \\
\hline \multirow[t]{3}{*}{ BFP } & 1 & $30.32^{3} \pm 0.43$ & $36.36 \pm 1.50$ & 0.001 & 29.49 & 31.18 & 33.54 & 39.41 \\
\hline & 2 & $42.95^{3} \pm 1.03$ & $33.43 \pm 1.66$ & 0.000 & 40.98 & 45.00 & 30.34 & 36.84 \\
\hline & 3 & $36.30 \pm 5.73$ & $35.47 \pm 1.65$ & 0.988 & 26.64 & 49.47 & 32.39 & 38.85 \\
\hline
\end{tabular}

${ }^{1} p=0.042 ;{ }^{2} p=0.000 ;{ }^{3} p=0.000 ;{ }^{4} p=0.025 ; \mathrm{BMI}$, Body Mass Index; WC, waist circumference; BFP, body fat percentage; CT, chemotherapy; SD, Standard Deviation; Group 1, women using tamoxifen for the first 3 years; Group 2, women using tamoxifen between 3 and 4 years; Group 3, women using TMX for more than 4 years. Data adjusted for age, smoking, alcohol consumption, physical activity, energy (kcal), and clinical stage. ${ }^{*} p$ calculated by ANOVA. Post hoc comparison (Sidak method)

over the years of endocrine treatment in the face of the increase of the number of long-term $\mathrm{BC}$ survivors and the many years of established endocrine therapy [3].

In this study, considering only women from group 1 (using TMX for the first 3 years), those that previously underwent CT had higher values of body fat and were more obese than those who did not undergone CT. The effect of CT interaction at different times of endocrine therapy with TMX on body parameters had not been reported in the literature before. Considering that the use of TMX starts in most cases after CT, the worst results for women who underwent CT may be due to the prolonged effects of chemotherapy and not for the effect of TMX. In a prospective and observational study performed with 272 French women treated with CT, greater weight changes were reported at 6 and 12 months after the end of this treatment [50], and the average weight gain in the first year after the end of the CT was $3 \mathrm{~kg}$ [51]. Such body modifications may be explained in part by the induction of $\mathrm{CT}$ in the reduction of energy expenditure [52], changes and perceptions of food due to the effects of nausea and changes in palatability [53], and negative nitrogen balance [54]. In addition, we may consider that the side effect of endocrine therapy with TMX on body weight, although still controversial, may exert an influence in this process. However, it is difficult to relate body modification entirely to TMX, since most studies of weight gain reports did not have a comparison group $[13,55,56]$.

Also, an important aspect of CT is the induction of ovarian failure by treatment toxicity, especially in women approaching menopause $[57,58]$, and in Brazil the mean age of menopause is 51 years old [59]. A study with women with $\mathrm{BC}$ in $\mathrm{CT}$ found an immediate reduction of ovarian blood flow after treatment, demonstrating a postmenopausal profile for most patients accompanied by related symptoms [60]. Thus, those perimenopause women who do CT, especially with anthracycline-based regimens compared to CMF [61], may enter menopause more frequently with $\mathrm{CT}$ and present earlier and induced symptoms already known from climacteric, such as changes in body composition [62, 63].

When analyzing women who did not have CT in this study, we verified that the highest nutritional risk and body fat did not occur in the group with at most 3 years of TMX use, but in women in the intermediate duration group, between 3 and 4 years. Results of a crosssectional study with american women found that the highest percentage of weight gain occurred after 3 years of TMX use; however, CT was not considered [4]. These results suggest that these women who do not have CT may have different reactions between them. First, the concentration of important metabolites of TMX oxidative metabolism, such as endoxifene, is related to the occurrence of side effects from drug use [4], suggesting the need for prospective studies to see if different concentrations occur throughout treatment and its relation to previous treatments, such as CT.

Also, food intake is an important modifiable factor contributing to changes in nutritional status and the risk of obesity in women with BC [52-54]. However, in our study, we found that women did not present statistically significant differences for the average amount of energy, carbohydrate and protein intake among the three groups evaluated. However, only significantly higher mean values for lipids were observed for women in group 1. Possibly, the preference for more palatable foods in this period, still resulting from the cytotoxicity of those who did CT [53], may have influenced this result. In addition, as a result of the several years proposed for endocrine 

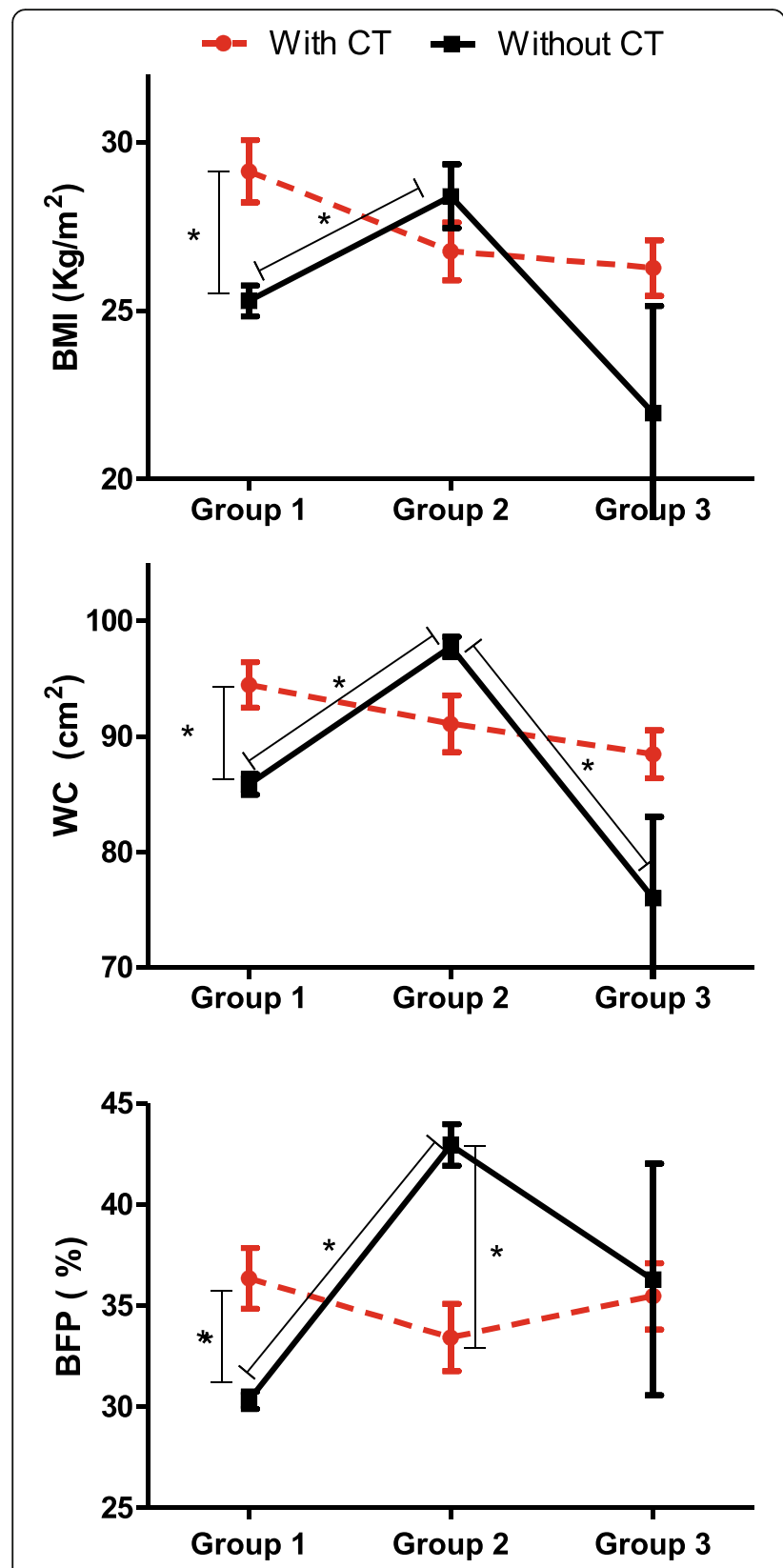

Fig. 2 Distribution of women using endocrine therapy with TMX categorized according to groups (1,2 and 3) and according to whether or not $C T$ was performed. Distribution of women with breast cancer, according to groups of TMX usage duration in a university hospital in the city of Uberlandia, Minas Gerais, Brazil, 2015-2016 ( $n=84$, BMl and $\left.W C_{;} n=74, B F P\right)$. Group 1, women using tamoxifen for the first 3 years; group 2, women using tamoxifen between 3 and 4 years; Group 3, women using tamoxifen for more than 4 years; BMI, Body Mass Index; $W C$, waist circumference; BFP, body fat percentage; $C T$, chemotherapy; ${ }^{*} p<0.05$ calculated by ANOVA. Post hoc comparison (Sidak method)

therapy [3], it has been shown that psychological factors such as anxiety and depression are common in endocrine therapy [64], and may interfere with changes in the dietary pattern [65]. There is a need for prospective studies to evaluate and consider these factors for better explaining these findings in view of the negative effects of obesity.

Additionally, we found altered values for TG and HDL$\mathrm{C}$, with HDL-C showing inadequate values in women in the first 3 years and between 3 and 4 years of treatment statistically significant between the three groups. In this sense, since central obesity is associated with several biochemical alterations, including decreased glucose tolerance, elevated serum insulin levels and lipid changes [41-43], blood assessments are important in this population, being a risk factor for many diseases associated with such changes, including diabetes mellitus and cardiovascular disease $[66,67]$.

In general, adjuvant therapy with $\mathrm{AI}$ is associated with better outcomes compared to TMX for postmenopausal women with endocrine-responsive BC. However, in many public hospitals from Brazil (as in our case), taken into consideration cost issues, AIs are reserved to be used only in high risk early BC patients. This approach is not all bad, considering findings from the Breast International Group Trial 1-98 comparing adjuvant TMX with letrozole which showed considerable less benefit of AI over TMX in patients presenting lower risk of recurrence $[68,69]$. However, many postmenopausal women with endocrine-responsive $\mathrm{BC}$ are still receiving TMX in low-resource hospitals. In addition, TMX has been chosen for patients presenting moderate to severe osteoporosis (which is not uncommon in post-menopausal women). Also, it is important to mention that central obesity becomes more prevalent after menopause, which may have distorted the results.

Possible limitations of this study should be considered. One limitation is the use of unequally weighted populations relative to the menopausal state that may at least in part interfere in the generalization of the study. Moreover, cross-sectional evaluation makes it impossible to establish causal relationships with changes in body composition and duration of TMX use along with the other variables. In this way, it would be important to obtain the usual weight before the beginning of the treatments for $\mathrm{BC}$, since that obesity may have had some correlation with $\mathrm{BC}$ incidence and some effect on the treatment regimen chosen in the first place, and that is a possible confounder when interpreting the data from this study. We did not evaluate the CT in relation to its different chemotherapeutic agents, in which they can respond differently to weight gain [70].

\section{Conclusions}

Our results suggest that women in endocrine therapy with TMX require nutritional monitoring throughout treatment with the need for targeted interventions at specific times. Women who have undergone $\mathrm{CT}$ prior to 
initiating endocrine therapy deserve special attention in the first 3 years of treatment. However, women who did not undergo CT had a higher nutritional risk in the intermediate treatment period (between 3 and 4 years). In view of the great benefit of endocrine therapy with TMX already established, which exceeds the negative effects on body composition, these results reinforce the importance of nutritional guidelines and multidisciplinary follow-up, taking into account previous treatments such as CT, thus ensuring that BMI and body composition are reduced or maintained within a healthy range. In addition, these strategies may contribute to a greater adherence to treatment and also better medication action.

\begin{abstract}
Abbreviations
24HR: 24-h dietary recall; AC: Adriamycin + Cyclophosphamide; BC: Breast cancer; BFP: Body fat percentage; BIA: Bioelectrical impedance; BMI: Body mass index; CMF: Cyclophosphamide, methotrexate, and 5-fluorouracil; CRP: C-Reactive protein; CT: Chemotherapy; FAC: Cyclophosphamide, doxorubicin, and 5-fluorouracil; G1: Well-differentiated tumor (low grade); G2: Moderately differentiated tumor (intermediate grade); G3: Poorly differentiated tumor (high grade); GEE: Generalized estimating equations; Group 1: Women using tamoxifen for the first 3 years; Group 2: Women using tamoxifen between 3 and 4 years; Group 3: Women using TMX for more than 4 years; HDL-C: High density lipoprotein; LDL-C: Low density lipoprotein; NR: Not reported; TG: Triglycerides; TMX: Tamoxifen; WBC: White blood cell count; WC: Waist circumference
\end{abstract}

\section{Acknowledgements}

To the volunteer women of this study.

\section{Funding}

This work was supported by Conselho Nacional de Desenvolvimento Científico e Tecnológico, Brasil (CNPq Grant number: 449,938/2014-0); Fundação de Amparo à Pesquisa do Estado de Minas Gerais (FAPEMIG); and Fundação PIO XII. The funders had no role in study design, data collection and analysis, decision to publish, or preparation of the manuscript.

\section{Availability of data and materials}

The datasets used and/or analyzed during the current study are available from the corresponding author on reasonable request.

\section{Authors' contributions}

MTML; CEP; YCPM: These authors contributed equally to this work: Conceived and designed the experiments; performed the experiments; analyzed the data; wrote the paper; read and approved the final manuscript. MAM: This author designed the experiments; analyzed the data; wrote and revised the paper; read and approved the final manuscript. PPLC; KPC; FSM: These authors also contributed equally to this work: Data collection; Analyzed the data; wrote and revised the paper; read and approved the final manuscript.

\section{Ethics approval and consent to participate}

This study was approved by the Human Research Ethics Committee of Federal University of Uberlandia (CEP/UFU) under protocol number 907.129/14 and all participants signed a free and informed consent form.

\section{Consent for publication}

Not applicable.

\section{Competing interests}

The authors have full control over the primary data and agree to allow the journal to review the data if requested. In addition, they declare no conflict of interest.

\section{Publisher's Note}

Springer Nature remains neutral with regard to jurisdictional claims in published maps and institutional affiliations.

\section{Author details}

${ }^{1}$ Graduate Program in Health Sciences, Federal University of Uberlandia, Avenida Pará, 1720 Bloco 2U, Campus Umuarama, Uberlandia, Minas Gerais CEP 38400-902, Brazil. ${ }^{2}$ Nutrition Course, Medical Faculty, Federal University of Uberlandia, Avenida Pará, 1720 Bloco 2U, Campus Umuarama, Uberlandia, Minas Gerais CEP 38400-902, Brazil. ${ }^{3}$ Faculty of Computing, Federal University of Uberlandia, Avenida Joao Naves de Avila, 2121, Campus Santa Monica, Uberlandia, Minas Gerais CEP 38400-902, Brazil. ${ }^{4}$ Department of Clinical Oncology, Clinic's Hospital, Federal University of Uberlandia, Avenida Pará, 1720, Setor de oncologia, sala 9 Campus Umuarama, Uberlandia, Minas Gerais CEP 38.405-320, Brazil. ${ }^{5}$ Department of Clinical Oncology, Graduate Program in Oncology, Palliative Care and Quality of Life Research Group (GPQual), Pio XII Foundation - Barretos Cancer Hospital, Rua Antenor Duarte Vilela, de 1301/1302 ao fim, Doutor Paulo Prata, Barretos, Sao Paulo CEP 14784-400, Brazil.

Received: 14 February 2017 Accepted: 17 August 2017

Published online: 29 August 2017

\section{References}

1. Siegel RL, Miller KD, Jemal A. Cancer statistics 2016. CA Cancer J Clin. 2016;66(1):7-30.

2. Early Breast Cancer Trialists Collaborative Group (EBCTCG), Davies C, Godwin J, Gray R, Clarke M, Cutter D, et al. Relevance of breast cancer hormone receptors and other factors to the efficacy of adjuvant tamoxifen: patientlevel meta-analysis of randomised trials. Lancet. 2011;378(9793):771-84.

3. Davies C, Pan H, Godwin J, Gray R, Arriagada R, Raina V, et al. Long-term effects of continuing adjuvant tamoxifen to 10 years versus stopping at 5 years after diagnosis of oestrogen receptor-positive breast cancer: ATLAS, a randomised trial. Lancet. 2013;381(9869):805-16.

4. Lorizio W, Wu AH, Beattie MS, Rugo H, Tchu S, Kerlikowske K, et al. Clinical and biomarker predictors of side effects from tamoxifen. Breast Cancer Res Treat. 2012;132(3):1107-18.

5. Vance V, Mourtzakis M, McCargar L, Hanning R. Weight gain in breast cancer survivors: prevalence, pattern and health consequences. Obes Rev. 2011;12(4):282-94.

6. Chen X, Lu W, Gu K, Chen Z, Zheng Y, Zheng W, et al. Weight change and its correlates among breast cancer survivors. Nutr Cancer. 2011;63(4):538-48.

7. Azrad M, Demark-Wahnefried W. The association between adiposity and breast cancer recurrence and survival: a review of the recent literature. Curr Nutr Rep. 2014;3(1):9-15.

8. San Felipe MJR, Martínez AA, Manuel-Y-Keenoy B. Influencia del peso corporal en el pronóstico de las supervivientes de cáncer de mama; abordaje nutricional tras el diagnóstico. Nutr Hosp. 2013;28(6):1829-41.

9. Kawai M, Minami Y, Nishino Y, Kukamachi K, Ohuchi N, Kakugawa Y. Body mass index and survival after breast cancer diagnosis in Japonese woman BMC Cancer. 2012;12:149.

10. Irwin ML, McTiernan A, Baumgartner RN, Baumgartner KB, Bernstein L, Gilliland FD, et al. Changes in body fat and weight after a breast cancer diagnosis: influence of demographic, prognostic, and lifestyle factors. I Clin Oncol. 2005;23(4):774-82.

11. Goodwin PJ, Ennis M, Pritchard KI, McCready D, Koo J, Sidlofsky S, et al. Adjuvant treatment and onset of menopause predict weight gain after breast cancer diagnosis. J Clin Oncol. 1999;17(1):120-9.

12. Tredan O, Bajard A, Meunier A, Roux P, Fiorletta I, Gargi T, et al. Body weight change in women receiving adjuvant chemotherapy for breast cancer: a French prospective study. Clin Nutr. 2010;29(2):187-91.

13. Saquib N, Flatt SW, Natarajan L, Thomson CA, Bardwell WA, Caan B, et al. Weight gain and recovery of pre-cancer weight after breast cancer treatments: evidence from the women's healthy eating and living (WHEL) study. Breast Cancer Res Treat. 2007;105(2):177-86.

14. Harvie MN, Campbell IT, Baildam A, Howell A. Energy balance in early breast cancer patients receiving adjuvant chemotherapy. Breast Cancer Res Treat. 2004;83(3):201-10.

15. Bender CM, Gentry AL, Brufsky AM, Casillo FE, Cohen SM, Dailey MM, et al. Influence of patient and treatment factors on adherence to adjuvante andocrine therapy in breast cancer. Oncol Nurs Forum. 2014;41(3):274-85.

16. Sheean PM, Hoskins K, Stolley M. Body composition changes in females treated for breast cancer: a review of the evidence. Breast Cancer Res Treat. 2012;135(3):663-80. 
17. Longcope C, Baker R, Johnston CC. Androgen and estrogen metabolism: relationship to obesity. Metabolism. 1986;35(3):235-7.

18. Bulun SE, Chen D, Moy I, Brooks DC, Zhao H. Aromatase, breast cancer and obesity: a complex interaction. Trends Endocrinol Metab. 2012;23(2):83-9.

19. Dee A, McKean-Cowdin R, Neuhouser ML, Ulrich C, Baumgartner RN, McTiernan A, et al. DEXA measures of body fat percentage and acute phase proteins among breast cancer survivors: a cross-sectional analysis. BMC Cancer. 2012;12:343.

20. Seynaeve C, Hille E, Hasenburg A, Rea D, Markopoulos C, Hozumi Y, et al. The impact of body mass index on the efficacy of adjuvant endocrine therapy in postmenopausal hormone sensitive breast cancer patients: exploratory analysis from the TEAM study. Cancer Res. 2010;70(Suppl 24):S2-3.

21. Bell KE, Di Sebastiano KM, Vance V, Hanning R, Mitchell A, Quadrilatero J, et al. A comprehensive metabolic evaluation reveals impaired glucose metabolism and dyslipidemia in breast cancer patients early in the disease trajectory. Clin Nutr. 2014;33(3):550-7.

22. Singh HK, Prasad MS, Kandasamy AK, Dharanipragada K. Tamoxifen-induced hypertriglyceridemia causing acute pancreatitis. J Pharmacol Pharmacother. 2016;7(1):38-40.

23. Jenaa SK, Suresha S, Sangamwarb AT. Modulation of tamoxifen-induced hepatotoxicity by tamoxifen-phospholipid complex. J Pharm Pharmacol. 2015;67(9):1198-206

24. Gaibar M, Fernández G, Romero-Lorca A, Novillo A, Tejerina A, Bandrés F, et al. Tamoxifen therapy in breast cancer: do apolipoprotein $E$ genotype and menopausal state affect plasma lipid changes induced by the drug? Int J Biol Markers. 2013;28(4):371-6.

25. Khosrow-Khavar F, Filion KB, Al-Qurashi S, Torabi N, Bouganim N, Suissa S, et al. Cardiotoxicity of Aromatase inhibitors and Tamoxifen in postmenopausal women with breast cancer: a systematic review and metaanalysis of randomized controlled trials. Ann Onc. 2016; doi:10.1093/ annonc/mdw673.

26. Ewer MS, Glück S. A woman's heart. A woman's heart: the impact of adjuvant endocrine therapy on cardiovascular health. Cancer. 2009;115(9): 1813-26.

27. van de Velde CJ, Rea D, Seynaeve C, Putter H, Hasenburg A, Vannetzel JM, et al. Adjuvant tamoxifen and exemestane in early breast cancer (TEAM): a randomised phase 3 trial. Lancet. 2011;377(9762):321-31.

28. Sestak I, Distler W, Forbes JF, Dowsett M, Howell A, Cuzick J. Effect of body mass index on recurrences in tamoxifen and anastrozole treated women: an exploratory analysis from the ATAC trial. J Clin Oncol. 2010;28(21):3411-5.

29. Faul F, Erdfelder E, Lang AG, Buchner A. G* power 3: a flexible statistical power analysis program for the social, behavioral, and biomedical sciences. Behav Res Methods. 2007;39(2):175-91.

30. WHO. World Health Organization. Physical status: the use and interpretation of anthropometry. Report of a WHO expert committee. Geneva: WHO Technical Report Series 854; 1995. http://www.who.int/childgrowth/publications/ physical_status/en. Accessed 2 Jan 2017.

31. WHO. World Health Organization. Active ageing - a police framework. Madrid: A Contribution of the World Health Organization to the second United Nations World Assembly on Aging. 2002. http://www.who.int/ ageing/publications/active_ageing/en. Accessed 10 June 2017

32. Lohamn TG, Going SB. Assessment of body composition and a energy balance. In: Lamb DR, Murray R, editors. Exercise, nutrition, and weight control. Perspective in exercise science and sports medicine, vol. 11; 1998. p. 61-105.

33. Kyle UG, Bosaeus I, De Lorenzo AD, Deurenberg P. Elia M, Gómez JM, et al. Composition of the ESPEN working group. Bioelectrical impedance analysispart I: review of principles and methods. Clin Nutr. 2004;23(5):1226-43.

34. BRASIL. Ministério da Saúde. Secretaria de Vigilância em Saúde. Departamento de Vigilância de Doenças e Agravos não Transmissíveis e Promoção da Saúde. Vigitel Brasil 2015: vigilância de fatores de risco e proteção para doenças crônicas por inquérito telefônico. Brasília; 2015. [Access 10 June 2017. Available: http://bvsms.saude.gov.br/bvs/publicacoes/ vigitel_brasil_2015.pdf

35. TACO. Tabela Brasileira de Composição de Alimentos. $4^{a}$ ed. rev. e ampl. Campinas: NEPA - UNICAMP; 2011.

36. USDA. United States Dietetic Association. Dietary guidelines for Americans 2005. Accessed 10 June 2017. Available: https://health.gov/ dietaryguidelines/dga2005/document/

37. Xavier HT, Izar MC, Faria Neto JR, Assad MH, Rocha VZ, Sposito AC, et al. Sociedade Brasileira de Cardiologia. V Diretriz Brasileira sobre Dislipidemias e Prevenção da Aterosclerose. Arq Bras Cardiol. 2013;101(Suppl. 1):1-20.
38. Diretrizes da Sociedade Brasileira de Diabetes: 2015-2016. AC Farmacêutica, São Paulo. 2016. http://www.diabetes.org.br/sbdonline/images/docs/ DIRETRIZES-SBD-2015-2016.pdf. Accessed 02 Jan 2017.

39. Lorenzi TF. Manual de Hematologia. Propedêutica e clínica. 3rd ed. São Paulo: Editora Médica Científica; 2003.

40. Sendur MAN, Aksoy S, Ozdemir NY, Zengin N, Yazici O, Sever AR, et al. Effect of body mass index on the efficacy of adjuvant tamoxifen in premenopausal patients with hormone receptor positive breast cancer. JBUON. 2016;21(1):27-34.

41. Schmitz KH, Ahmed RL, Hannan PJ, Yee D. Safety and efficacy of weight training in recent breast cancer survivors to alter body composition, insulin, and insulin-like growth factor axis proteins. Cancer Epidemiol Biomark Prev. 2005;14(7):1672-80.

42. Jiralerspong S, Kim ES, Dong W, Feng L, Hortobagyi GN, Giordano SH. Obesity, diabetes, and survival outcomes in a large cohort of early-stage breast cancer patients. Ann Oncol. 2013;24(10):2506-14.

43. Goodwin PJ, Ennis M, Pritchard Kl, Trudeau ME, Koo J, Taylor SK, et al. Insulin- and obesity-related variables in early-stage breast cancer: correlations and time course of prognostic associations. J Clin Oncol. 2012; 30(2):164-71.

44. Ewertz M, Jensen MB, Gunnarsdottir KA, Jakobsen EH, Nielsen D, Stenbygaard $L E$, et al. Effect of obesity on prognosis after early-stage breast cancer. J Clin Oncol. 2011;29(1):25-31.

45. van den Brandt PA, Spiegelman D, Yaun SS, Adami HO, Beeson L, Folson $A R$, et al. Pooled analysis of prospective cohort studies on height, weight, and breast cancer risk. Am J Epidemiol. 2000;152(6):514-27.

46. Howell A, Cuzick J, Baum M, Buzdar A, Dowsett M, Forbes JF, et al. Results of the ATAC (Arimidex, Tamoxifen, alone or in combination) trial after completion of 5 years' adjuvant treatment for breast cancer. Lancet. 2005; 365(9453):60-2.

47. Fisher B, Costantino JP, Wickerham DL, Redmond CK, Kavanah M, Cronin WM, et al. Tamoxifen for prevention of breast cancer: report of the National Surgical Adjuvant Breast and bowel project P-1 study. J Natl Cancer Inst. 1998:90(18):1371-88.

48. Bayley JP, Devilee P. The Warburg effectin in 2012. Curr Opin Oncol. 2012;24(1):62-7.

49. Bayley JP, Devilee P. Warburg tumours and the mechanisms of mitochondrial tumour supressor genes.Barkingup the right tree? Curr Opin Genet Dev. 2010;20(3):324-9.

50. Trédan O, Bajard A, Meunier A, Roux P, Fiorletta I, Gargi T, et al. Body weight change in women receiving adjuvant chemotherapy for breast cancer: a French prospective study. Clin Nutr. 2010;29(2):187-91.

51. Judson GM, Braun B, Jerry DJ, Mertens W. Weight gain following breast cancer diagnosis: implication and proposed mechanisms. World I Clin Oncol. 2014;5(3):272-82.

52. Demark-Wahnefried W, Peterson BL, Winer EP, Marks L, Aziz N, Marcom PK, et al. Changes in weight, body composition, and factors influencing energy balance among premenopausal breast cancer patients receiving adjuvant chemotherapy. J Clin Oncol. 2001;19(9):2381-9.

53. Custódio IDD, Marinho EC, Gontijo CA, Pereira TSS, Paiva CE, Maia YC. Impact of chemotherapy on diet and nutritional status of women with breast cancer: a prospective study. PLoS One. 2016;11(6):e0157113.

54. Gudny Geirsdottir O, Thorsdottir I. Nutritional status of cancer patients in chemotherapy; dietary intake, nitrogen balance and screening. Food Nutr Res. 2008; doi:10.3402/fnr.v52i0.1856.

55 Kumar NB, Allen K, Cantor A, Cox CE, Greenberg H, Shah S, et al. Weight gain associated with adjuvant tamoxifen therapy in stage I and II breast cancer: fact or artifact? Breast Cancer Res Treat. 1997;44(2):135-43.

56. Fisher B, Dignam J, Bryant J, DeCillis A, Wickerham DL, Wolmark N, et al. Five versus more than five years of tamoxifen therapy for breast cancer patients with negative lymph nodes and estrogen receptor-positive tumors. J Natl Cancer Inst. 1996:88(21):1529-42.

57. Vriens IJ, De Bie AJ, Aarts MJ, de Boer M, van Hellemond IE, Roijen JH, et al. The correlation of age with chemotherapy-induced ovarian function failure in breast cancer patients. Oncotarget. 2017; doi:10.18632/oncotarget.14532.

58 Ben-Aharon I, Granot T, Meizner I, Hasky N, Tobar A, Rizel S, et al. Long-term follow-up of chemotherapy-induced ovarian failure in young breast cancer patients: the role of vascular toxicity. Oncologist. 2015;20(9):985-91.

59. Pedro AO, Pinto Neto AM, Paiva LH, Osis MJ, Herdy E. Age at natural menopause among Brazilian women: results from a population-based survey. Cad Saude Publica. 2003;19(1):17-25. 
60. Rechia F, Necozione S, Bratta M, Rosselli M, Guerriero G, Rea S. LH-RH analogues in the treatment of young women with early breast cancer: long-term follow-up of a phase II study. Int J Oncol. 2015;46(3):1354-60.

61. Tham YL, Sexton K, Weiss H, Elledge R, Friedman LC, Kramer R. The rates of chemotherapy-induced amenorrhea in patients treated with adjuvant doxorubicin and Cyclophosphamide followed by a taxane. Am J Clin Oncol. 2007;30(2):126-32

62. Cho GJ, Lee JH, Park HT, et al. Postmenopausal status according to years since menopause as an independent risk factor for the metabolic syndrome. Menopause. 2008;15(3):524-9.

63. Sowers $\mathrm{M}$, Zheng $\mathrm{H}$, Tomey $\mathrm{K}$, et al. Changes in body composition in women over six years at midlife: ovarian and chronological aging. J Clin Endocrinol Metab. 2007;92(3):895-901.

64. Zainal NZ, Nick-Jaafar NR, Baharudin A, Sabki ZA, Ng CG. Prevalence of depression in breast cancer survivors: a systematic review of observational studies. Asian Pac J Cancer Prev. 2013;14(4):2649-56.

65. Quirk SE, Williams LJ, O'Neil A, Pasco JA, Jacka FN, Housden S, et al. The association between diet quality, dietary patterns and depression in adults: a systematic review. BMC Psychiatry. 2013;13:175.

66. van Noord PAH, Seidell JC, den Tonkelaar I, Baanders-van Halewijn EA, Ouwehand ZJ. The relationship between fat distribution and some chronic diseases in 11,825 women participating in the DOM project. Int J Epidemiol. 1990;19(3):564-70.

67. Folsom AR, Prineas RJ, Kaye SA, Soler JT. Body fat distribution and selfreported prevalence of hypertension, heart attack, and other heart disease in older women. Int J Epidemiol. 1989:18(2):361-7.

68. Viale G, Giobbie-Hurder A, Regan MM, Coates AS, Mastropasca MG, Dell'Orto $P$, et al. Prognostic and predictive value of centrally reviewed Ki-67 labeling index in postmenopausal women with endocrine-responsive breast cancer: results from breast international group trial 1-98 comparing adjuvant tamoxifen with letrozole. J Clin Oncol. 2008;26(34):5569-75.

69. Viale G, Regan MM, Dell'Orto P, Mastropasca MG, Maiorano E, et al. Which patients benefit most from adjuvant aromatase inhibitors? Results using a composite measure of prognostic risk in the BIG 1-98 randomized trial. Ann Oncol. 2011:22(10):2201-7.

70. Lankester KJ, Phillips JE, Lawton PA. Weight gain during adjuvant and neoadjuvant chemotherapy for breast cancer: anaudit of 100 women receiving FEC or CMF chemotherapy. Clin Oncol (R Coll Radiol). 2002;14(1):64-7.

\section{Submit your next manuscript to BioMed Central and we will help you at every step:}

- We accept pre-submission inquiries

- Our selector tool helps you to find the most relevant journal

- We provide round the clock customer support

- Convenient online submission

- Thorough peer review

- Inclusion in PubMed and all major indexing services

- Maximum visibility for your research

Submit your manuscript at www.biomedcentral.com/submit 